\title{
APLIKASI SISTEM INFERENSI FUZZY METODE TSUKAMOTO DALAM PENILAIAN MUTU BENIH PADI
}

\author{
Diasta Risi Esa Annisa, Mutia Nur Estri \\ diastarisi@ymail.com \\ Universitas Jenderal Soedirman
}

\begin{abstract}
In this paper, we use the Fuzzy inference system of Tsukamoto method to determine the rice seeds quality. The input variables are production average, the age of plant, and fallen seeds, and the output variable is rice seed quality. The output is determined through 4 steps i.e. fuzzification, determine fuzzy rules, and defuzzification. The results show that the best quality of rice seed is IR 64 and the worst is Lusi.
\end{abstract}

\section{Keyword: Rice seeds, Fuzzy Inference System, Tsukamoto method}

\begin{abstract}
ABSTRAK. Pada makalah in, kita menggunakan system inferensi fuzzy metode Tsukamoto untuk menentukan mutu benih padi. Variabel input yang digunakan adalah rata-rata hasil, umur tanaman, dan kerontokan, dan variabel output yang digunakan adalah mutu benih padi. Output ditentukan melalui 4 tahapan, yaitu fuzzifikasi, penerapan aturan-aturan fuzzy, dan defuzzifikasi. Hasil memperlihatkan bahwa padi jenis IR 64 merupakan padi dengan nilai mutu terbaik, sedangkan padi jenis Lusi merupakan padi dengan nilai mutu terendah.
\end{abstract}

Kata kunci : Benih padi, sistem inferensi fuzzy, metode Tsukamoto

\section{PENDAHULUAN}

\subsection{Latar Belakang}

Benih padi adalah gabah yang dihasilkan dengan cara dan tujuan khusus untuk disemaikan menjadi pertanaman (Aak,1990). Dalam proses budidaya padi, petani selalu menghendaki tanaman yang bermutu baik dengan produktivitas yang tinggi. Sistem yang menangani masalah perbenihan khususnya mutu benih di Indonesia adalah Balai Pengawasan dan Sertifikasi Benih (BPSB).

Di Indonesia terdapat berbagai macam varietas benih padi dan beragam pula mutunya. Petani di Indonesia sebagian menggunakan varietas benih padi dengan mutu sedang seperti benih padi cisadane, IR 64, cilamaya muncul, ciherang, sintanur cigeulis, logawa, lusi, dan situbagendit. Berdasarkan 
keberagaman varietas benih padi, maka diperlukan alat bantu untuk mendapatkan mutu benih padi yang diharapkan sesuai dengan kriteria-kriteria yang diberikan. Salah satu alternatif untuk membantu penilaian mutu benih padi adalah dengan menggunakan sistem inferensi fuzzy karena penentuan mutu benih padi dapat dikategorikan ke dalam suatu permasalahan yang samar atau tidak pasti. Ketidakpastian ini dikarenakan penentuan mutu benih padi dapat berbeda-beda berdasarkan pada kriteria-kriteria yang diberikan. Terdapat beberapa metode pada sistem inferensi fuzzy antara lain metode Mamdani, metode Sugeno, dan metode Tsukamoto. Di dalam sistem inferensi fuzzy, metode Tsukamoto terdapat hubungan sebab akibat yang menggunakan aplikasi nilai monoton dan output hasil inferensi dari tiap-tiap aturan diberikan secara tegas (crisp) berdasarkan $\alpha$ predikat (fire strength). Selain itu, syarat keanggotaan yang digunakan harus simetri sehingga tepat untuk menggambarkan fenomena alam, seperti penilaian mutu benih padi. Oleh karena itu, pada makalah ini sistem inferensi fuzzy metode Tsukamoto digunakan untuk menilai mutu benih padi yang tepat.

\section{METODE PENELITIAN}

\subsection{Data}

Data yang digunakan dalam penelitian ini adalah data benih padi yang diambil dari Khikmah, 2013 pada Tabel 2.1.

Tabel 2.1 Data Kriteria Benih Padi

\begin{tabular}{|l|c|c|c|}
\hline \multicolumn{1}{|c|}{ Nama Benih Padi } & $\begin{array}{c}\text { Rata-rata } \\
\text { Hasil (ton/ha) }\end{array}$ & $\begin{array}{c}\text { Umur Tanaman } \\
\text { (hari) }\end{array}$ & $\begin{array}{c}\text { Kerontokan } \\
\text { (per 100 bulir) }\end{array}$ \\
\hline Cisadane & 5 & 135 & 35 \\
\hline IR 64 & 5 & 130 & 35 \\
\hline Cimalaya Muncul & 6 & 130 & 25 \\
\hline Ciherang & 6 & 120 & 35 \\
\hline Sintanur & 6 & 120 & 35 \\
\hline Cigeulis & 5 & 120 & 35 \\
\hline Logawa & 6,8 & 115 & 50 \\
\hline Lusi & 4,5 & 135 & 50 \\
\hline Situ Bagendit & 5,5 & 115 & 35 \\
\hline
\end{tabular}




\subsection{Prosedur Penelitian}

Perhitungan yang digunakan meliputi perhitungan manual dan perhitungan menggunakan program. Perhitungan secara manual dilakukan dengan membuat dan menganalisis himpunan fuzzy untuk input dan output berdasarkan data benih padi yang ada, menentukan aturan-aturan fuzzy yang akan digunakan, membuat FIS dengan metode Tsukamoto, melakukan tahap defuzzifikasi dengan metode rata-rata terpusat, dan menganalisis nilai yang dihasilkan FIS. Sementara itu, perhitungan menggunakan program dilakukan dengan merancang ekspresi program berdasarkan FIS yang telah dibuat, memasukkan nilai tiap input ke dalam program untuk dilakukan perhitungan program, menganalisis hasil output FIS metode Tsukamoto yang diperoleh dari perhitungan program, dan menganalisis hasil output antara perhitungan manual dan perhitungan program.

\section{HASIL DAN PEMBAHASAN}

\subsection{Variabel Input dan Output}

Penentuan penilaian mutu benih padi membutuhkan sejumlah kriteria yang digunakan untuk mendukung proses pengambilan keputusan. Menurut (Khikmah, 2013: 35-40 berdasarkan pada data dinas pertanian kabupaten Banyumas), kriteria penilaian mutu benih padi dapat dilihat pada Tabel 3.1 sampai dengan Tabel 3.3.

a. Kriteria rata-rata hasil

Tabel 3.1Kriteria rata-rata hasil

\begin{tabular}{|c|c|}
\hline Rata-rata Hasil (ton/ha) & Penilaian Mutu \\
\hline kurang dari 4,0 & Kurang \\
\hline 4,0 s/d 7,0 & Sedang \\
\hline Lebih dari 7,0 & Baik \\
\hline
\end{tabular}

b. Kriteria umur tanaman

Tabel 3.2 Kriteria umur tanaman

\begin{tabular}{|c|c|}
\hline Umur Tanaman (hari) & Penilaian Mutu \\
\hline kurang dari 100 & Baik \\
\hline 100 s/d 140 & Sedang \\
\hline lebih dari 140 & Kurang \\
\hline
\end{tabular}

c. Kriteria Kerontokan 
Tabel 3.3 Kriteria Kerontokan

\begin{tabular}{|c|c|}
\hline Kerontokan ( per 100 bulir) & Penilaian Mutu \\
\hline kurang dari 20 & Baik \\
\hline 20 s/d 50 & Sedang \\
\hline lebih dari 50 & Kurang \\
\hline
\end{tabular}

Oleh karena itu, ditentukan semesta pembicaraan seperti pada Tabel 3.4. Berdasarkan Tabel 3.4 ditentukan bahwa kriteria rata-rata hasil, umur tanaman, dan kerontokan merupakan variabel input. Sementara itu, penilaian mutu merupakan variabel output.

Tabel 3.4 Semesta Pembicaraan

\begin{tabular}{|c|c|l|c|}
\hline Variabel & Nama Variabel & Notasi & Semesta Pembicaraan \\
\hline \multirow{3}{*}{ Input } & Rata-rata hasil & $\mathrm{Rh}$ & {$[0, \infty)$} \\
\cline { 2 - 4 } & Umur tanaman & $\mathrm{Ut}$ & {$[0, \infty)$} \\
\cline { 2 - 4 } & Kerontokan & $\mathrm{Rk}$ & {$[0, \infty)$} \\
\hline \multirow{2}{*}{ Output } & Mutu benih & $\mathrm{Mb}$ & {$[0, \infty)$} \\
\hline
\end{tabular}

\subsection{Fuzzifikasi}

Lingkup dalam sistem inferensi fuzzy merupakan keseluruhan nilai variabel yang boleh digunakan. Berdasarkan Tabel 3.4 dapat dicari lingkup untuk

Tabel 3.5 Himpunan input dan output fuzzy

\begin{tabular}{|c|c|c|c|}
\hline VARIABEL & HIMPUNAN FUZZY & \multirow{2}{*}{ NOTASI } & \multirow{2}{*}{$\begin{array}{c}\text { LINGKUP } \\
\text { dalam (ton/ha) }\end{array}$} \\
\hline INPUT & Rata-rata hasil & & \\
\hline & 1. Sedikit & Rh_sdk & {$[0,5,5]$} \\
\hline & 2. Sedang & Rh_sdg & {$[4,7]$} \\
\hline & 3. Banyak & Rh_byk & {$[5,5,17]$} \\
\hline & Umur tanaman & & dalam (hari) \\
\hline & 1. Pendek & Ut_pdk & {$[0,120]$} \\
\hline & 2. Sedang & Ut_sdg & {$[100,140]$} \\
\hline & 3. Panjang & Ut_pjg & {$[120,180]$} \\
\hline & Kerontokan & & dalam (/100 bulir) \\
\hline & 1. tahan rontok & Rk_thn & {$[0,35]$} \\
\hline & 2. agak tahan & Rk_agk & {$[20,50]$} \\
\hline & 3. mudah rontok & Rk_mdh & {$[35,100]$} \\
\hline OUTPUT & Mutu benih & & dalam $(\%)$ \\
\hline & 1. kurang & Mb_krg & {$[0,70]$} \\
\hline & 2. $\quad$ sedang & Mb_sdg & {$[60,70]$} \\
\hline & 3. baik & Mb_bk & {$[70,100]$} \\
\hline
\end{tabular}


masing-masing himpunan fuzzy yang dibentuk.Himpunan fuzzy yang dibentuk untuk setiap variabel input dan output dapat dilihat pada Tabel 3.5.

Fungsi keanggotaan untuk setiap himpunan fuzzy mempunyai interval antara 0 sampai 1. Nilai 0 menunjukkan tidak adanya keanggotaan $(0 \%)$ di dalam himpunan fuzzy, sedangkan nilai 1 menunjukkan keanggotaan mutlak (100\%) di dalam himpunan fuzzy. Fungsi keanggotaan untuk masing-masing himpunan fuzzy adalah sebagai berikut:

a. Rata-rata hasil

$$
\begin{gathered}
\mu_{R_{h_{-} \text {sdk }}}\left(x_{1}\right)= \begin{cases}1, & \text { jika } 0 \leq x_{1} \leq 4 \\
\frac{5,5-x_{1}}{1,5}, & \text { jika } 4<x_{1}<5,5 \\
0, & \text { jika } x_{1} \geq 5,5\end{cases} \\
\mu_{R_{h_{-} \text {ddg }}}\left(x_{1}\right)= \begin{cases}\frac{1,}{1,5}, & \text { jika } x_{1}=5,5 \\
\frac{x_{1}-4}{1,5}, & \text { jika } 4<x_{1}<5,5 \\
0, & \text { jika } 0 \leq x_{1} \leq 4 \text { atau } x_{1} \geq 7 \\
\mu_{R_{h_{-} \text {byk }}}\left(x_{1}\right)= \begin{cases}1, & \text { jika } x_{1} \geq 7\end{cases} \\
\frac{x_{1}-5,5}{1,5}, & \text { jika } 5,5<x_{1}<7 \\
0, & \text { jika } 0 \leq x_{1} \leq 5,5\end{cases}
\end{gathered}
$$

b. Umur tanaman

$$
\mu_{U_{t-p d k}}\left(x_{2}\right)= \begin{cases}1, & \text { jika } 0 \leq x_{2} \leq 100 \\ \frac{120-x_{2}}{20}, & \text { jika } 100<x_{2}<120 \\ 0, & \text { jika } x_{2} \geq 120\end{cases}
$$




$$
\begin{aligned}
& \mu_{U_{t} \leq \mathrm{ddg}}\left(x_{2}\right)=\left\{\begin{array}{cl}
1, & \text { jika } x_{2}=120 \\
\frac{x_{2}-100}{20}, & \text { jika } 100<x_{2}<120 \\
\frac{140-x_{2}}{20}, & \text { jika } 120<x_{2}<140 \\
0, & \text { jika } 0 \leq x_{2} \leq 100 \text { atau } x_{2} \geq 140
\end{array}\right. \\
& \mu_{U_{t-\mathrm{p} j g}}\left(x_{2}\right)= \begin{cases}1, & \text { jika } x_{2} \geq 140 \\
\frac{x_{2}-120}{20}, & \text { jika } 120<x_{2}<140 \\
0, & \text { jika } 0 \leq x_{2} \leq 140\end{cases}
\end{aligned}
$$

c. Kerontokan

$$
\begin{aligned}
& \mu_{R_{k_{-} \text {thn }}}\left(x_{3}\right)= \begin{cases}1, & \text { jika } 0 \leq x_{3} \leq 20 \\
\frac{35-x_{3}}{15}, & \text { jika } 20<x_{3}<35 \\
0, & \text { jika } x_{3} \geq 35\end{cases} \\
& \mu_{R_{k_{- \text {agk }}}}\left(x_{3}\right)= \begin{cases}1, & \text { jika } x_{3}=35 \\
\frac{x_{3}-20}{15}, & \text { jika } 20<x_{3}<35 \\
\frac{50-x_{3}}{15}, & \text { jika } 35<x_{3}<50 \\
0, & \text { jika } 0 \leq x_{3} \leq 20 \text { atau } x_{3} \geq 50 \\
1, & \text { jika } x_{3} \geq 50\end{cases} \\
& \mu_{R_{k_{-} \text {man }}}\left(x_{3}\right)= \begin{cases}\frac{x_{3}-35}{15}, & \text { jika } 35<x_{3}<50 \\
0, & \text { jika } 0 \leq x_{3} \leq 35\end{cases}
\end{aligned}
$$

d. Mutu benih

$$
\mu_{M_{\mathrm{b} \_ \text {krg }}}(z)= \begin{cases}1, & \text { jika } 0 \leq z \leq 60 \\ \frac{70-z}{10}, & \text { jika } 60<z<70 \\ 0, & \text { jika } z \geq 70\end{cases}
$$




$$
\begin{aligned}
& \mu_{M_{\text {b } \_ \text {dg }}}(z)=\left\{\begin{array}{cl}
1, & \text { jika } z=70 \\
\frac{z-60}{10}, & \text { jika } 60<z<70 \\
\frac{80-z}{10}, & \text { jika } 70<z<80 \\
0, & \text { jika } 0 \leq z \leq 60 \text { atau } z=80
\end{array}\right. \\
& \mu_{M_{\text {b_bk }}}(z)=\left\{\begin{array}{cl}
1, & \text { jika } z=80 \\
\frac{z-70}{10}, & \text { jika } 70<z<80 \\
0, & \text { jika } 0 \leq z \leq 70
\end{array}\right.
\end{aligned}
$$

Setelah input dan output difuzzifikasi, selanjutnya dibentuk aturan-aturan fuzzy yang akan digunakan dalam sistem inferensi fuzzy.

\subsection{Aturan Dasar Fuzzy}

Berdasarkan himpunan-himpunan fuzzy yang telah dibuat maka terdapat 27 aturan implikasi fuzzy untuk pemilihan benih padi. Aturan-aturan tersebut antara lain :

$R_{5}=$ IF rata-rata banyak AND umur tanaman sedang AND agak tahan rontok THEN mutu benih sedang $R_{14}=$ IF rata-rata sedang AND umur tanaman sedang AND agak tahan rontok THEN mutu benih sedang

\subsection{Penilaian Mutu Benih Padi dengan Perhitungan Manual}

Perhitungan manual dilakukan dengan menggunakan input rata-rata hasil, umur tanaman, dan kerontokan benih padi, sedangkan output yang dihasilkan merupakan persentase mutu benih padi. Pada perhitungan ini hanya diambil satu contoh, yaitu benih padi Ciherang dengan langkah-langkah sebagai berikut:

1) Menghitung nilai kenggotaan pada setiap varibel input dan output

a. Rata-rata hasil

$$
\mu_{R_{h_{-} s d k}}(6)=0, \mu_{R_{h_{-} s d}}(6)=\frac{7-6}{1,5}=0,6667, \mu_{R_{h_{-} \mathrm{byk}}}(6)=\frac{6-5,5}{1,5}=0,3333 .
$$


b. Umur tanaman

$$
\mu_{U_{t_{-} p d k}}(120)=0, \mu_{U_{t_{-} \mathrm{dd}}}(120)=1, \mu_{U_{t_{-}} \mathrm{pjg}}(120)=0 .
$$

c. Kerontokan

$$
\mu_{R_{k_{-} \text {thn }}}(35)=0, \mu_{R_{k_{-} \text {agk }}}(35)=1, \mu_{R_{k_{-} \text {mdd }}}(35)=0 .
$$

2) Menghitung $\alpha$-predikat dan nilai output pada setiap aturan yang memenuhi nilai keanggotaannnya tidak sama dengan nol

- Untuk $R_{5}$,

$$
\begin{aligned}
\alpha_{14} & =\min \left\{\mu_{R_{h_{-} \mathrm{byk}}}\left(x_{1}\right), \mu_{U_{\mathrm{t} \_s d g}}\left(x_{2}\right), \mu_{R_{k_{-} a g k}}\left(x_{3}\right)\right\} \\
& =\min \left\{\mu_{R_{h_{-} \mathrm{byk}}}(6), \mu_{U_{\mathrm{t}_{-} s d g}}(120), \mu_{R_{k_{-} a g k}}(35)\right\} \\
& =\min \{(0,3333),(1),(1)\} \\
& =0,3333
\end{aligned}
$$

dan

$$
\frac{z_{14}-60}{10}=\alpha_{14} \Leftrightarrow \frac{z_{14}-60}{10}=0,3333 \Leftrightarrow z_{14}-60=3,333 \Leftrightarrow z_{14}=63,333 .
$$

- Untuk $R_{14}$, dengancara yang sama, diperoleh $=0,6667 \quad \alpha_{14}$ dan $z_{14}=73,3333$.

3) Melakukan defuzzifikasi

Defuzzifikasi dilakukan dengan metode rata-rata terbobot. Nilai dari rata-rata terbobot $z_{0}$ adalah

$$
z_{0}=\frac{\alpha_{5} z_{5}+\alpha_{14} z_{14}}{\alpha_{5}+\alpha_{14}}=\frac{(0,3333)(63,333)+(0,6667)(73,3333)}{0,3333+0,6667}=70 .
$$

Dengan demikian, mutu benih padi Ciherang adalah 70\%. Ini berarti bahwa benih padi Ciherang bermutu sedang.

\subsection{Penilaian mutu benih padi dengan Perhitungan Program}

Perhitungan menggunakan program dilakukan dengan langkah-langkah sebagai berikut:

1. Memanggil function yang digunakan di dalam Command Windows, yaitu hasilok.m. 
2. Tampilan antarmuka functionhasilok.m, seperti disajikan pada Gambar 3.1.

3. Memasukkan nilai dari tiap-tiap input. Untuk benih padi Ciherang pada ratarata hasil dimasukkan nilai 6 , pada umur tanaman dimasukkan nilai 120 , dan pada kerontokan dimasukkan nilai 35. Kemudian menekan tombol “HITUNG”untuk melakukan perhitungan program.

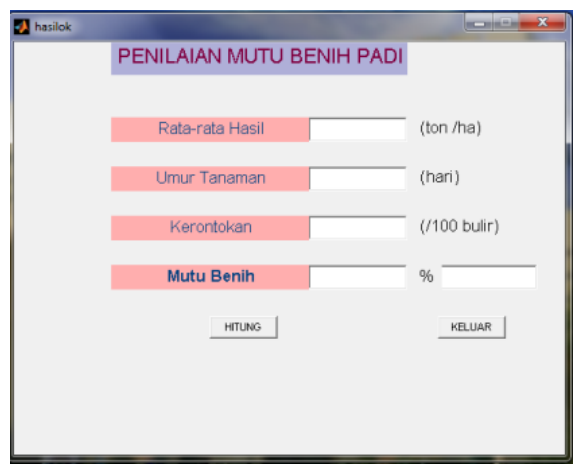

Gambar 3.1 Tampilan antarmuka function hasilok.m

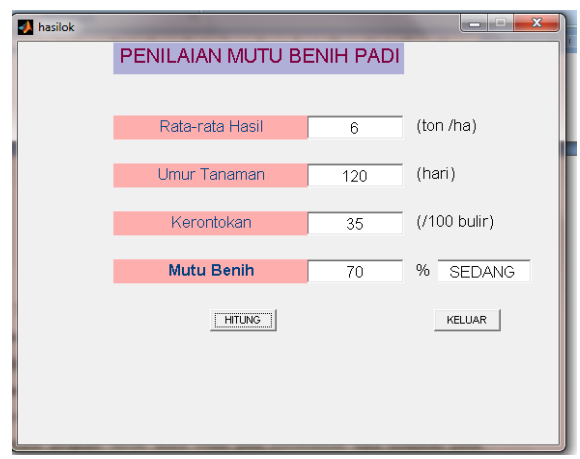

Gambar 3.2 Tampilan antarmuka setelah menekan tombol "HITUNG"

Tabel 3.6 Hasil penilaian mutu benih padi

\begin{tabular}{|l|c|c|c|c|c|}
\hline $\begin{array}{c}\text { Nama } \\
\text { Benih Padi }\end{array}$ & $\begin{array}{c}\text { Rata-rata } \\
\text { Hasil (ton/ha) }\end{array}$ & $\begin{array}{c}\text { Umur Tanaman } \\
\text { (hari) }\end{array}$ & $\begin{array}{c}\text { Kerontokan } \\
\text { (per100 bulir) }\end{array}$ & $\begin{array}{c}\text { Mutu } \\
\text { Benih (\%) }\end{array}$ & $\begin{array}{c}\text { Mutu } \\
\text { benih }\end{array}$ \\
\hline Cisadane & 5 & 135 & 35 & 68,2407 & Sedang \\
\hline IR 64 & 5 & 130 & 35 & 71 & Sedang \\
\hline $\begin{array}{l}\text { Cimalaya } \\
\text { Muncul }\end{array}$ & 6 & 130 & 25 & 68,7073 & Sedang \\
\hline Ciherang & 6 & 120 & 35 & 70 & Sedang \\
\hline Sintanur & 6 & 120 & 35 & 70 & Sedang \\
\hline Cigeulis & 5 & 120 & 35 & 70 & Sedang \\
\hline Logawa & 6,8 & 115 & 50 & 70,1491 & Sedang \\
\hline Lusi & 4,5 & 135 & 50 & 64,6296 & Kurang \\
\hline $\begin{array}{l}\text { Situ } \\
\text { Bagendit }\end{array}$ & 5,5 & 115 & 35 & 70 & Sedang \\
\hline
\end{tabular}


Dari Tabel 3.6, Nampak tidak terdapat perbedaan antara hasil perhitungan menggunakan program dan perhitungan secara manual. Selain itu dapat disimpulkan benih padi IR 64 merupakan benih padi dengan mutu tertinggi dan benih padi Lusi merupakan benih padi dengan mutu terendah. Dengan demikian, rata-rata dari data benih padi yang ada bermutu sedang.

\section{KESIMPULAN \& SARAN}

\subsection{Kesimpulan}

Sistem inferensi fuzzy metode Tsukamoto dapat diaplikasikan untuk membantu menentukan penilaian mutu benih padi dengan 3 variabel input (ratarata hasil, umur tanaman, dan kerontokan) dan 1 variabel output (mutu benih). Perhitungan untuk penilaian mutu benih padi tersebut dapat dilakukan secara manual maupun secara komputasi dengan menggunakan program. Berdasarkan data yang digunakan, hasil penilaian menunjukkan bahwa benih padi IR 64 merupakan benih padi dengan mutu terbaik dan benih padi Lusi merupakan benih padi dengan mutu terendah.

\subsection{Saran}

Saran yang dapat diberikan oleh penulis adalah sebagai berikut:

1. Mutu benih padi dapat ditentukan menggunakan sistem inferensi fuzzy metode Tsukamoto dapat dikembangkan dengan penambahan kriteria dari data benih padi yang ada. Hal ini dikarenakan kriteria dalam menentukan mutu benih padi dapat bertambah seiring dengan kemajuan teknologi.

2. Penelitian ini belum masuk dalam tahap penggunaan di masyarakat. Oleh karena itu, perlu dikembangkan program yang dapat diaplikasikan secara umum dan dapat digunakan oleh masyarakat.

\section{UCAPAN TERIMAKASIH}

Terima kasih diucapkan kepada Dr. Idha Sihwaningrum, M.Sc.St. yang banyak memberikan masukan dan saran pada proses penyusunan makalah ini. 


\section{DAFTAR PUSTAKA}

Aak. 1990. Budidaya Benih Tanaman Padi.

Badan Standarisasi Nasional. 2003. Benih Padi. Balai Besar Penelitian Tanaman Padi. Jakarta.

Cox, E. 1994. The Fuzzy Systems Handbook: a Practictitioner's guide to Building, Using, and Maintaining Fuzzy System. London: Academic Press Limited.

Khikmah, A N. 2013. Penerapan Metode Analytical Hierarchy Process dalam Pemilihan Kualitas Benih Padi Sawah.

Sivanandam, S.N., Sumathi, S. dan Deepa, S.N., 2007. Introduction to Fuzzy Logic using Matlab. Jerman: Springer. 